\title{
Mesenchymal stem cells-derived vascular smooth muscle cells release abundant levels of osteoprotegerin
}

\author{
F. Corallini, ${ }^{1}$ A. Gonelli, ${ }^{2}$ F. D'Aurizio, ${ }^{3}$ M.G. di lasio, ${ }^{2}$ M. Vaccarezza ${ }^{4}$ \\ ${ }^{1}$ Department of Biomedicine, University of Trieste, Trieste; ${ }^{2}$ Department of Morphology and Embryology, \\ University of Ferrara, Ferrara; ${ }^{3}$ Interdepartmental Center of Regenerative Medicine (CIME), University of \\ Udine, Udine; ${ }^{4}$ Department of Health and Movement Science, University of Cassino, Cassino (FR), Italy
}

(C)2009 European Journal of Histochemistry

Although several studies have shown that the serum levels of osteoprotegerin (OPG) are significantly elevated in patients affected with atherosclerotic lesions in coronary and peripheral arteries, the cellular source and the role of OPG in the physiopathology of atherosclerosis are not completely defined. Therefore, we aimed to investigate the potential contribution of mesenchymal stem cells in the production/release of OPG. OPG was detectable by immunohistochemistry in aortic and coronary atherosclerotic plaques, within or in proximity of intimal vascular smooth muscle cells (SMC). In addition, bone marrow mesenchymal stem cell (MSC)-derived vascular SMC as well as primary aortic SMC released in the culture supernatant significantly higher levels of OPG with respect to MSCderived endothelial cells (EC) or primary aortic EC. On the other hand, in vitro exposure to full-length human recombinant OPG significantly increased the proliferation rate of aortic SMC cultures, as monitored by bromodeoxyuridine incorporation. Taken together, these data suggest that OPG acts as an autocrine/paracrine growth factor for vascular SMC, which might contribute to the progression of atherosclerotic lesions.

Key words: osteoprotegerin; mesenchymal stem cells; smooth muscle cells; atherosclerosis.

Correspondence: Mauro Vaccarezza,

Department of Health and Movement Science, University of Cassino, viale Bonomi snc, 03043

Cassino (FR), Italy

Tel +39.0776.2994420.

Fax +39.0776.2993839

E-mail: m.vaccarezza@unicas.it

Paper accepted on November 4, 2008

European Journal of Histochemistry

2009; vol. 53 issue 1 (January-March): 19-24
A therosclerosis is a form of chronic low-grade inflammation resulting from interaction between modified lipoproteins, monocytederived macrophages and vascular smooth muscle cells (SMC) (Libby, 2002). Although the prevalent view is that intimal vascular SMC found in atherosclerotic plaques derive from cells migrating from the tunica media of the same artery (Libby, 2002), accumulating data indicate that also bone marrow (BM) mesenchymal stem cells (MSC), also known as multipotent stromal cells, have the potential to migrate in sites of vascular injury or inflammation and to differentiate into vascular SMC (Hillebrands et al., 2001, Li et al., 2001).

Several studies have clearly demonstrated that the serum levels of the soluble member of the TNFreceptor super-family osteoprotegerin (OPG) are elevated in patients with coronary or carotid artery disease, especially those with clinically unstable atherosclerotic plaques (Jono et al., 2002, Schoppet et al., 2003, Secchiero et al., 2006a, Shin et al., 2006, Abedin et al., 2007, Avignon et al., 2007, Gulbiken et al., 2007, Kadoglu et al., 2008a, Omland et al., 2008). Despite the fact that neither the cellular source nor the physiological and pathological effects of elevated serum levels of OPG are well understood, a possible pathogenic link between elevated levels of OPG and inflammation has been suggested by recent in vitro studies of our and others research groups (Zauli et al., 2007, Mangan et al. 2007).

Therefore, in order to assess the potential contribution of MSC in the pathogenesis of atherosclerosis, we have evaluated the release of OPG in the culture supernatants of BM-derived MSC differentiating along the vascular SMC or endothelial cell (EC) lineages. In addition, we have investigated the effect of recombinant human OPG on aortic SMC proliferation. 


\section{Materials and Methods}

\section{Immunohistochemical detection of OPG}

Samples of human ascending aortas and coronary vessels with atherosclerotic plaques were obtained from the Thoracic Surgery Department of University of Udine, as approved by the local research ethics committee. All specimens were fixed with $4 \%$ formaldehyde, paraffin-embedded and cut in serial sections of $5 \mu \mathrm{m}$. Tissue morphology was evaluated by hematoxylin and eosin staining. Immunohistochemical detection of OPG was performed by using anti-human OPG Ab (clone 69127; R\&D Systems, Minneapolis, MN) and the Super Sensitive TMPolymer HRP IHC detection system (Bio Genex, San Ramon, CA), according to the manufacturer's instructions. 3,3 diaminobenzidine (DAB) was used as a chromogen, with subsequent nuclear counterstaining with hematoxylin. Staining evaluation was essentially qualitative by visual inspection of the samples by microscope.

\section{Cell cultures}

BM MSC, obtained from BM samples as previously described (Beltrami et al., 2007), were cultured on fibronectin-coated dishes in expansion medium containing 10\% FBS. In order to induce MSC-differentiation into SMC and EC, MSC were exposed to standardized differentiation-inducing conditions, as previously described (Beltrami et al., 2007). Expression of lineage-specific markers was monitored by immunofluorescence analysis with anti-von Willebrand Factor and anti- $\alpha$-smooth muscle actin (SMA; Dako, Copenhagen, Denmark) Abs. Primary human aortic vascular EC and SMC were obtained by Lonza (Walkersville, MD) and used between passages 4 and 8. OPG released in culture supernatants was measured by using a sandwich-type enzyme-linked immunosorbent assay (ELISA) kit, purchased from Alexis Biochemicals (Lausen, Switzerland). The sensitivity of the kit used was $2.8 \mathrm{pg} / \mathrm{mL}$ and the intra- and inter-assay coefficients of variation were $9 \%$ and $<10 \%$, respectively. For cell cycle analysis, SMC were made in a quiescent state by using serum-reduced ( $0.1 \%$ FBS) medium, treated with recombinant OPG (R\&D Systems), and then incubated with 5bromodeoxyuridine (BrdU; Sigma, Saint Louis, MO). Next, anti-BrdU Ab bounded to BrdU incorporated into newly synthesized DNA was detected by fluorescein isothiocyanate-conjugated secondary
Ab, as described (Secchiero et al., 2006b). Cells were stained with propidium iodide (PI) and analyzed by flow cytometry; live cells were gated tightly using forward and side scatter, as described (Vitale et al., 1997).

\section{Statistical analysis}

Comparison of group means was performed by Bonferroni and Student's $T$ test methods. Statistical significance was defined as $p<0.05$.

\section{Results}

\section{OPG is expressed in vascular SMC of atherosclerotic aortic and coronary plaques}

Immunohistochemical analysis demonstrated very low levels of OPG immunostaining in normal vessels (Figure $1 \mathrm{~A}$ ). On the other hand, a striking $O P G$ staining was observed in sections of aortic and coronary plaques, mainly confined to the fibrous cap (Figure 1 A). A strong cellular immunoreactivity in the atherosclerotic lesions was accompanied by a faint OPG expression in the interstitial space, according to the fact that $O P G$ is a secreted protein (Zauli and Secchiero, 2006). A parallel immunohistochemical analysis performed on serial histological sections with $\alpha$-smooth muscle actin (SMA) Ab indicated a preponderance of vascular SMC in the atherosclerotic fibrous cap (Figure 1 B). In particular, a good correspondence was observed between the elongated cells expressing $O P G$ and cells identified as vascular SMC (Figure $1 \mathrm{~B}$ ).

\section{Bone marrow MSC-derived SMC and primary aortic SMC release high levels of OPG}

Since it has been previously established that BM MSC can differentiate into either vascular EC or SMC (Hegner et al., 2005, Kashiwakura et al., 2003), we next investigated the ability of MSCderived SMC and EC to produce and release OPG in culture (Figure 2). Undifferentiated MSC (day 0 ) released detectable amounts of $O P G$ in their culture supernatants. While induction of differentiation along the endothelial lineage did not substantially modulate the amount of OPG released, the production/release of OPG showed a progressive and sustained increase paralleling the degree of SMC differentiation (Figure 2). Consistently with these findings, proliferating human aortic SMC released in culture supernatant significantly 

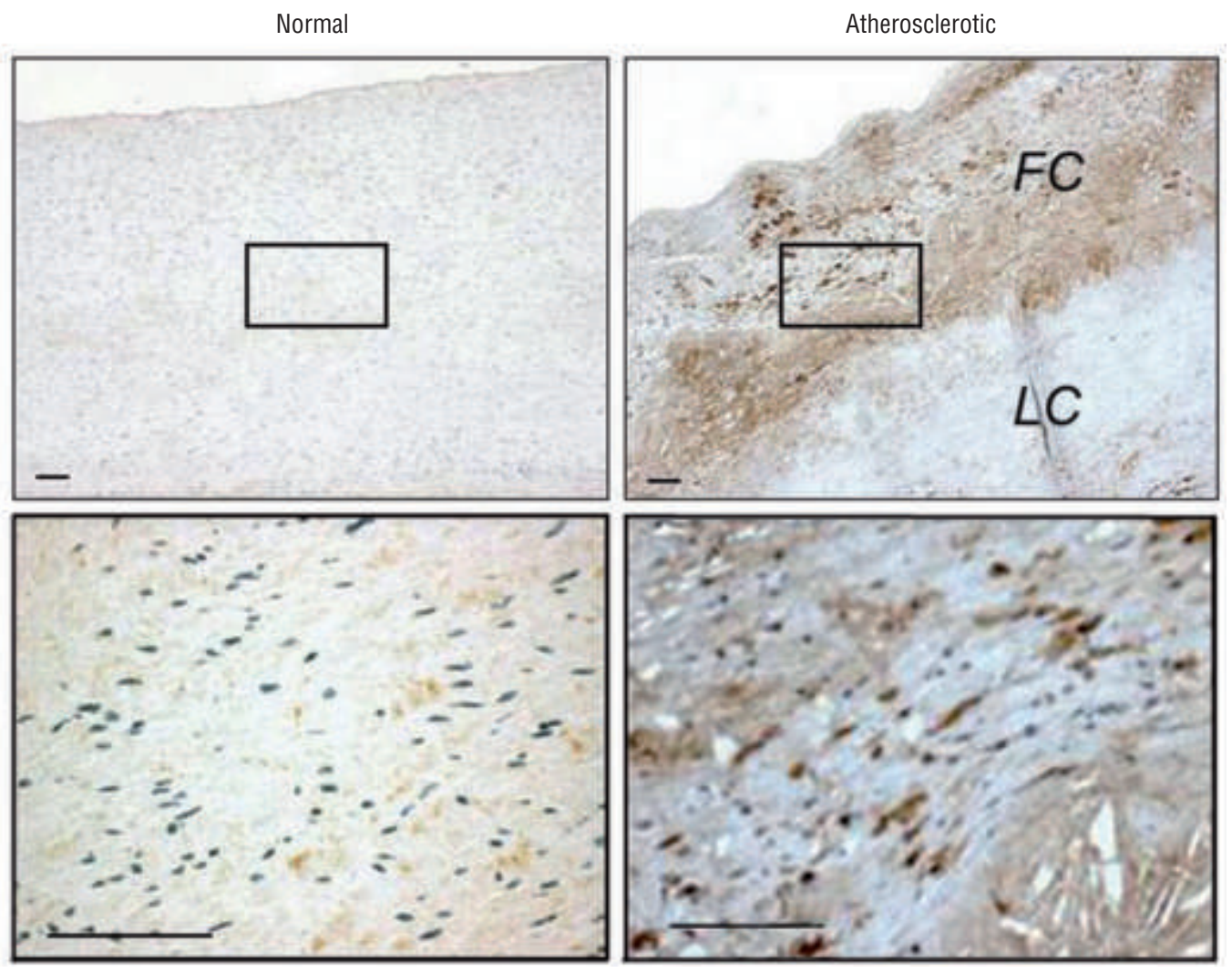

B

Atherosclerotic: SMA

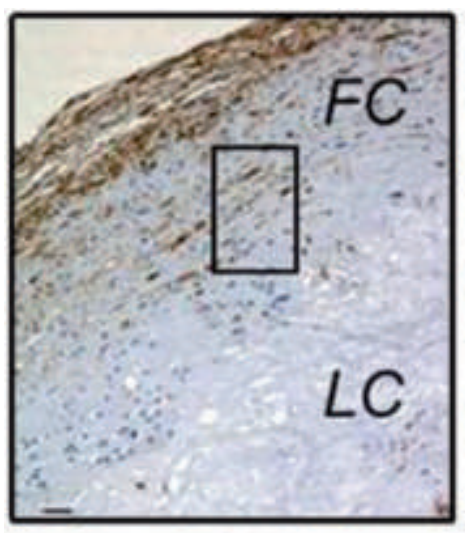

SMA

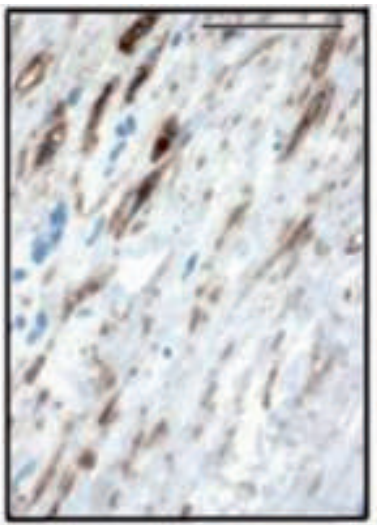

$O P G$

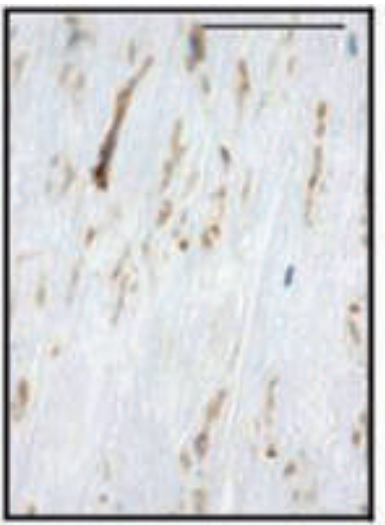

Figure 1. OPG expression in SMC of human atherosclerotic plaques. (A) immunohistochemical detection of OPG in samples of human ascending aortas with or without (normal) atherosclerotic plaque. FC, Fibrous cap; LC, Lipidic core. (B) comparison of immunohistochemical staining of a plaque performed with $\alpha$-smooth muscle actin (SMA) and OPG Abs indicates a good correspondence between the elongated cells expressing OPG and the SMC of atherosclerotic fibrous cap (FC). Scale bar: $100 \mu \mathrm{m}$. Representative pictures are shown. $(p<0.01)$ greater amounts of OPG with respect to aortic EC (Figure 2). Moreover, in agreement with recent findings demonstrating that recombinant OPG stimulates the proliferation of human pulmonary SMC (Lawrie et al., 2008), we could confirm that recombinant $O P G$ also stimulates the proliferation of aortic SMC (data not shown). Thus, vascular SMC represent the major cell type involved in the production of OPG in atherosclerotic lesions and therefore OPG could act as a paracrine/autocrine growth factor for vascular SMC. 

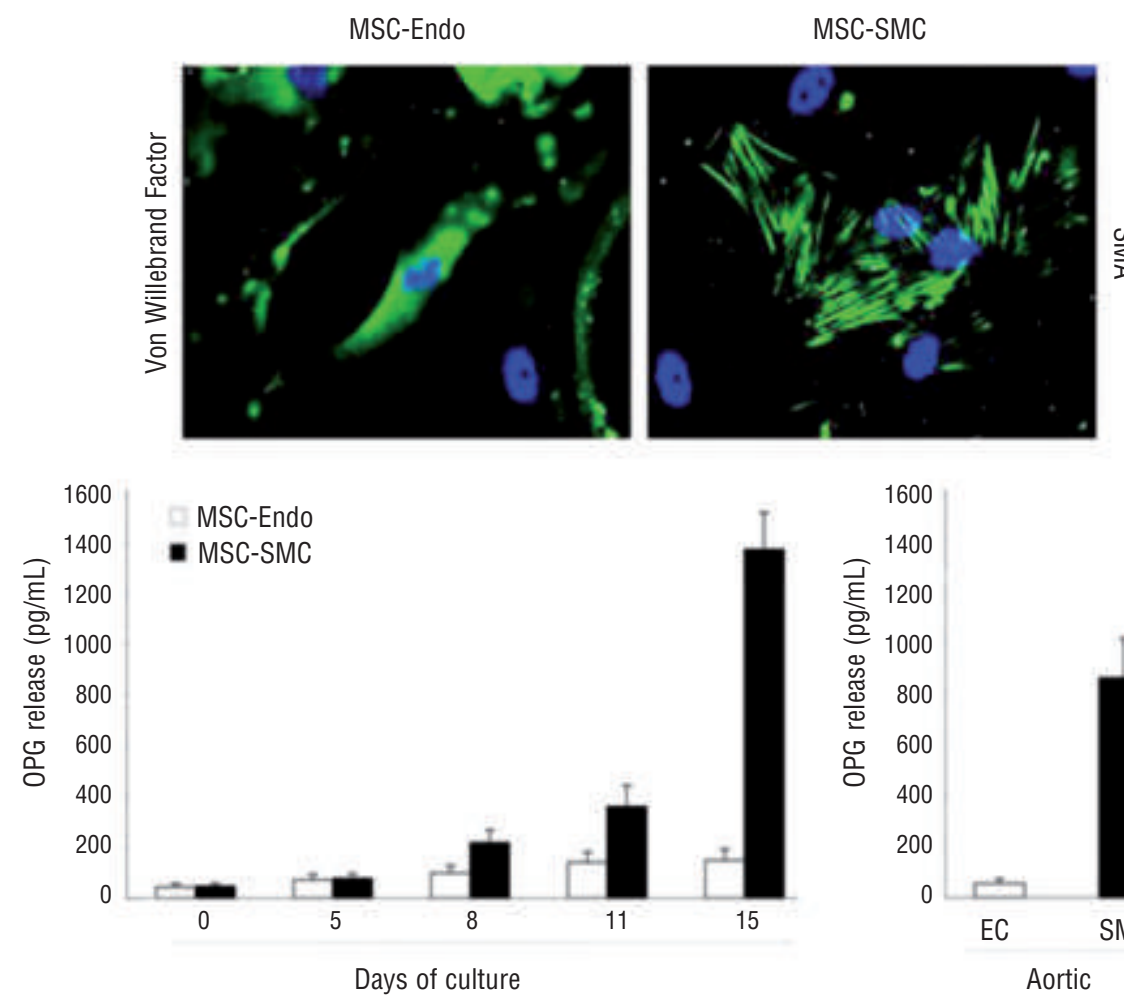

\section{Discussion}

Previous studies have shown that the expression and release of OPG by vascular cells is markedly up-regulated in response to inflammatory cytokines, such as TNF- $\alpha$ and platelet-derived growth factor (Zhang et al., 2002, Olesen et al., 2005). Conversely, OPG production is inhibited by PPAR- $\gamma$ ligands (Fu et al., 2002, Kadoglou et al., 2008b), agents associated with anti-inflammatory and anti-atherogenic effects in vitro and in vivo. In this context, our current demonstration that BM MSC spontaneously and progressively increase the production of OPG when differentiating along the SMC lineage is of particular interest. Moreover, the observation that OPG was predominantly detected in vascular SMC within the atherosclerotic plaques, suggests that vascular SMC play a major role in releasing OPG also in vivo. Our assumption is nevertheless indirect because a simultaneous expression for $\alpha$-actin and OPG was not assessed at the same time in our experiments. The potential ability of recombinant $O P G$ to significantly increase the proliferation rate of aortic SMC suggests that OPG could act as an autocrine/paracrine growth factor for vascu-
Figure 2. High levels of OPG are released by BM MSC-derived SMC and primary aortic SMC. BM MSC were induced to differentiate into endothelial (MSCEndo) and SMC (MSC-SMC). Culture differentiation was monitored by immunofluorescence analysis of lineage-specific markers: von Willebrand Factor for endothelial cells and $\alpha$-SMA for myocytes (both in green). DAPI was used in all fluorescent images to label nuclei in blue. Original magnification 40X. Release of OPG in culture supernatants was measured by ELISA at different time-points of culture. OPG released by aortic EC and SMC cultures is also shown. Measurements were done in duplicate and normalized for cell number. Data is expressed as means \pm SD of results from three independent experiments.
Iar SMC. In the context of our study, it is noteworthy that BM-derived MSC are able to engraft all layers of atherosclerotic plaques but not normal segments and could play double roles in the progress of atherosclerosis (Caplice et al., 2003). Differentiating into $\mathrm{EC}$, they contribute to regenerate the damaged endothelial layer, whereas differentiating into SMC, they contribute to worsen the atherosclerotic lesion (Caplice et al., 2003). Therefore one mechanism by which MSC of bone marrow origin may contribute to atherosclerotic progression is through the release of OPG, which could act as a paracrine/autocrine growth factor for vascular SMC. OPG could also contribute to worsen the degree of atherosclerosis by inhibiting the TNF family member TRAIL (Vitovski et al., 2007), which displays anti-inflammatory activity in vitro (Zauli et al., 2003) and anti-atherosclerotic activity in vivo, as documented by studies in the apo-E null mice model (Secchiero et al., 2006b).

In conclusion, our data suggests that OPG produced by MSC-derived vascular SMC can significantly influence the elevated OPG serum levels and may induce the progression of atherosclerosis by promoting proliferation of vascular SMC. 


\section{Acknowledgements}

This study was supported by MIUR-PRIN 20052007 (to M.V.) and University of Trieste-Progetto Giovani Ricercatori 2007 (to F.C.).

\section{References}

Abedin M, Omland T, Ueland T, Khera A, Aukrust $\mathrm{P}$, Murphy SA, et al. Relation of osteoprotegerin to coronary calcium and aortic plaque. Am J Cardiol 2007;99:513-8.

Avignon A, Sultan A, Piot C, Mariano-Goulart D. Thuan Dit Dieudonné JF, Cristol JP et al. Osteoprotegerin: a novel independent marker for silent myocardial ischemia in asymptomatic diabetic patients. Diabetes Care 2007;30:2934-9.

Beltrami AP, Cesselli D, Bergamin N, Marcon P, Rigo S, Puppato E, et al. Multipotent cells can be generated in vitro from several adult human organs (heart, liver, and bone marrow). Blood 2007;110:3438-46.

Caplice N M, Bunch TJ, Stalboerger PG, Wang S, Simper D, Miller DV, et al. Smooth muscle cells in human coronary atherosclerosis can originate from cells administered at marrow transplantation. Proc Natl Acad Sci USA 2003;100:4754-9.

Fu M, Zhang J, Lin Yg Y, Zhu X, Wilsson TM, Chen YE. Activation of peroxisome proliferator-activated receptor $\gamma$ inhibits osteoprotegerin gene expression in human aortic smooth muscle cells. Biochem Biophys Res Commu 2002;294:597-601.

Hegner B, Weber M, Dragun D, Schulze-Lohoff E. Differential regulation of smooth muscle markers in human bone marrow-derived mesenchymal stem cells. J Hypertens 2005;23:1191-202.

Hillebrands $\mathrm{JL}$, Klatter FA, Van den Hurk BM, Popa ER, Nieuwenhuis $P$, Rozing J. Origin of neointimal endothelium and alpha actin-positive smooth muscle cells in transplant arteriosclerosis. J Clin Invest 2001;107:1411-22.

Guldiken B, Guldiken S, Turgut B, Turgut N, Demir M, Celik Y et al. Serum osteoprotegerin levels in patients with acute atherothrombotic stroke and lacunar infarct. Thromb Res 2007;120:511-6.

Jono S, Ikari Y, Shioi A, Mori K, Miki T, Hara K, et al. Serum osteoprotegerin levels are associated with the presence and severity of coronary artery disease. Circulation 2002;106:1192-4.

Kadoglou NP, Gerasimidis T, Golemati S, Kapelouzou A, Karayannacos $P E$, Liapis CD. The relationship between serum levels of vascular calcification inhibitors and carotid plaque vulnerability. J Vasc Surg. 2008a;47:55-62.

Kadoglou NP, Gerasimidis T, Moumtzouoglou A, Kapelouzou A, Sailer $N$, Fotiadis $G$, et al. Intensive lipid-lowering therapy ameliorates novel calcification markers and GSM score in patients with carotid stenosis. Eur J Vasc Endovasc Surg. 2008b;35:661-8.

Kashiwakura Y, Katoh Y, Tamayose K, Konishi H, Takaya N, Yuhara S, et al. Isolation of bone marrow stromal cell-derived smooth muscle cells by a human SM22 alpha promoter: in vitro differentiation of putative smooth muscle progenitor cells of bone marrow. Circulation 2003; 107:2078-81.

Li J, Han X, Jiang J, Zhong R, Williams GM, Pickering JG, et al.
Vascular smooth muscle cells of recipient origin mediate intimal expansion after aortic allo-transplantation in mice. Am J Pathol 2001;158:1943-7.

Lawrie A, Waterman E, Southwood M, Evans D, Suntharalingam J, Francis $S$ et al. Evidence of a role for osteoprotegerin in the pathogenesis of pulmonary arterial hypertension. Am $J$ Pathol 2008;172:256-64.

Libby P. Inflammation in atherosclerosis. Nature 2002;420:868-74.

Mangan SH, Campenhout AV, Rush C, Golledge J. Osteoprotegerin upregulates endothelial cell adhesion molecule response to tumor necrosis factor-a associated with induction of angiopoietin-2. Cardiovasc Res 2007;76:494-505.

Olesen P, Ledet T, Rasmussen LM. Arterial osteoprotegerin: increased amounts in diabetes and modifiable synthesis from vascular smooth muscle cells by insulin and TNF-alpha. Diabetologia 2005;48:5618.

Omland T, Ueland T, Jansson AM, Persson A, Karlsson T, Smith C, et al. Circulating osteoprotegerin levels and long-term prognosis in patients with acute coronary syndromes. J Am Coll Cardiol 2008; 51:627-33.

Schoppet M, Sattler AM, Schaefer JR, Herzum M, Maisch B, Hofbauer LC. Increased osteoprotegerin serum levels in men with coronary artery disease. J Clin Endocrinol Metab 2003;88:1024-8.

Secchiero P, Corallini F, Pandolfi A, Consoli A, Candido R, Fabris B, et al. An increased osteoprotegerin (OPG) serum release characterizes the early onset of diabetes mellitus and may contribute to endothelial cell dysfunction. Am J Pathol 2006;169:2236-44.

Secchiero P, Barbarotto E, Tiribelli M, Zerbinati C, di Iasio MG, Gonelli $A$, et al. Functional integrity of the p53-mediated apoptotic pathway induced by the nongenotoxic agent nutlin-3 in B-cell chronic lymphocytic leukemia (B-CLL). Blood 2006;107: 4122-9.

Secchiero P, Candido R, Corallini F, Zacchigna S, Toffoli B, Rimondi E, et al. Systemic TRAIL delivery shows anti-atherosclerotic activity in apoE-null diabetic mice. Circulation 2006;114:1522-30.

Shin JY, Shin YG, Chun CH. Elevated serum osteoprotegerin levels are associated with vascular endothelial dysfunction in type 2 diabetes. Diabetes Care 2006;29:1664-6.

Vitale M, Zamai L, Falcieri E, Zauli G, Gobbi P, Santi S, et al. IMP dehydrogenase inhibitor, tiazofurin, induces apoptosis in K562 human erythroleukemia cells. Cytometry 1997;30:61-6.

Vitovski S, Phillips JS, Sayers J, Croucher PI. Investigating the interaction between osteoprotegerin and RANKL or TRAIL: evidence for a pivotal role for osteoprotegerin in regulating two distinct pathways. J Biol Chem 2007;282:31601-9.

Zauli G, Corallini F, Bossi F, Fischetti F, Durigutto P, Celeghini C, et al. Osteoprotegerin increases leukocyte adhesion to endothelial cells both in vitro and in vivo. Blood 2007;110:536-43.

Zauli G, Pandolfi A, Gonelli A, Di Pietro R, Guarnieri S, Ciabattoni G, et al. Tumor necrosis factor-related apoptosis-inducing ligand (TRAIL) sequentially up-regulates nitric oxide and prostanoid production in primary human endothelial cells. Circulation Res 2003; 92:732-40.

Zauli G, Secchiero P. The role of the TRAIL/TRAIL receptors system in hematopoiesis and endothelial cell biology. Cyt Growth Fact Rev 2006;17:245-57.

Zhang J, Fu M, Myles D, Zhu X, Du J, Cao X, et al. PDGF induces osteoprotegerin expression in vascular smooth muscle cells by multiple signal pathways. FEBS Lett 2002;521:180-4. 
F. Corallini et al. 